\title{
Bond Behavior of GFRP-Concrete Under Long-term Exposure to Aggressive Environments
}

\author{
Yulong Zheng ${ }^{1}$, Mingzhi $\mathrm{Ni}^{2}$, Chunhua $\mathrm{Lu}^{3 *}$, Tianshu $\mathrm{Chu}^{2}$ and Xiaolong $\mathrm{Wu}^{2}$
}

Received 14 August 2020, accepted 15 November 2020

doi:10.3151/jact.18.730

\begin{abstract}
The experimental results of the bond behavior between glass fiber reinforced polymer (GFRP) bars and concrete under several aggressive environments were studied. To give a comprehensive and comparative evaluation, a total 60 GFRP bar-concrete pullout specimens were divided into a control group and a treated group being immersed in tap water, alkaline and saline solutions for up to 270 days. The influences from aggressive environment, resin type and exposure period on the bond strength, together with the degradation mechanism and failure mode were explored. The time-dependent test results showed a clear decrease in the bond strength of treated group, with notably various degradation trends during different exposure periods. It is found that the saline solution induced the average bond strength loss of all corresponding specimens as $51.5 \%$ at 270 days, followed by alkaline solution (39.5\%) and tap water $(29.0 \%)$.
\end{abstract}

\section{Introduction}

Steel corrosion is considered to be the primary cause for performance degradation of concrete structure, which results in high maintenance and reinforcement costs (Koch et al. 2002; Ruan et al. 2020; Lu et al. 2020). In order to mitigate this problem and further improve the structural durability, fiber reinforced polymer (FRP) bar, as one new high-performance composite material made of continuous fiber and resin, is selected as one kind of internal reinforcing bar used in concrete structures, since FRP bars generally have the advantages of high stiffness weight ratio, high strength weight ratio, low cost performance ratio and excellent corrosion resistance (Robert et al. 2009; Yan et al. 2016). Many studies about mechanical behavior of concrete structures configuring basalt FRP (BFRP) (Elgabbas et al. 2016; Altalmas et al. 2015; Ma et al. 2019; Ge et al. 2020), carbon FRP (CFRP) (Borosnyoi 2015) and glass FRP (GFRP) (Bazli et al. 2017; Yan and Lin 2017) through experiment and FEM analysis (Bui et al. 2018) have been implemented in recent years, to explore the feasibility of applying FRP rebar in concrete structures instead of steel rebar.

It is widely recognized that bond strength plays a crucial role in reinforced bars' performance, because it affects many properties of concrete structure, such as bearing capacity and ductility (Zhang et al. 2020; Taha et al. 2020). There is clear difference between the bond

\footnotetext{
${ }^{1}$ Professor, Faculty of Civil Engineering and Mechanics, Jiangsu University, Zhenjiang 212013, P. R. China.

${ }^{2}$ Master's course student, Faculty of Civil Engineering and Mechanics, Jiangsu University, Zhenjiang 212013, P. R. China.

${ }^{3}$ Deputy Dean, Faculty of Civil Engineering and Mechanics Jiangsu University, Zhenjiang 212013, P. R. China. *Corresponding author, E-mail: Ich79@ujs.edu.cn
}

behavior from FRP bar and steel bar in concrete. It has been revealed that the bond behavior of FRP bar in concrete is influenced by many factors. For instance, Baena et al. (2009) designed 88 pullout test-pieces according to the ACI guide test methods (ACI 2004), from which, it was found that the concrete strength, diameter and surface treatment of FRP bar had effects on bond strength. Moreover, there was a tendency that FRP bars with larger diameter have lower bond strength. A database from 682 pullout tests was created by Yan et al. (2016) and it was concluded that the bond strength had relationships with critical factors, containing compression strength and covering layer thickness of concrete, size and embedment length of GFRP bar. Based on the pullout tests, Gu et al. (2016) suggested that the surface thread of optimal GFRP bar has the gap as 0.8 times of bar diameter and the depth as $1 \mathrm{~mm}$ in order to obtain the optimal bond strength.

Recently, the GFRP bars were developed to be a promising alternative for the traditional steel bars in reinforced concrete structures, owing to their lower production costs than those of BFRP and CFRP bars (Micelli and Nanni 2004). In general, GFRP bars are often adopted in engineering structures suffering deteriorations from severe ambient conditions, such as elevated temperature, freeze-thaw solution, chloride salts, saline and moisture environments (Robert et al. 2009; Bazli et al. 2017; Yan and Lin 2017; Baena et al. 2009; Masmoudi et al. 2011; Zhou et al. 2012; Taha et al. 2020). As the bond durability of GFRP bar reinforced concrete might be affected by the harsh environments, some studies have been carried out to explore the influence of corrosive environment on the bond behavior. Masmoudi et al. (2011) studied the effect of temperature from 20 to $80^{\circ} \mathrm{C}$ on the bonding properties between GFRP bars and concrete. It was found that the bond strength decreased by $14 \%$ after 8 months of thermal loading at $80^{\circ} \mathrm{C}$ compared with the result obtained at $20^{\circ} \mathrm{C}$. Yan et al. 
(2017) studied the bond properties of GFRP bars in concrete under freeze-thaw cycles. The test results revealed that via 75 freeze-thaw cycles, the reduction rate of bond strength varied from $12 \%$ to $3 \%$ when the covering layer thickness of concrete increased from 3 times to 4.5 times of the bar diameter. It is worth noting that the bond strengths of GFRP-concrete after exposure in aggressive solution environments are significantly different from above studies. Bazli et al. (2017) concluded from the experimental results of GFRP bar reinforced concrete that a reduction of bond strength appeared after exposure for 150 days in the alkaline and sea water solutions (loss at 10\% and 9\%, respectively). However, Zhou et al. (2012) tested pullout specimens exposed to conditioning solution medium for 90 days, while found an increment of bond strength occurred in environments like alkaline solution (increase by $13 \%$ ) and saline solution (increase by $8 \%$ ). This is possibly attributed to the influence from the concrete strength increment within the short exposure period of 90 days. Therefore, it can be learned from previous studies that the experimental results related to influences from conditioning solution environments on the bond strength of GFRP-concrete exhibit inconsistency. Further, to some extent there is contradiction due to the differences in concrete material, GFRP bar's property, aggressive solution and exposure period adopted in studies of different researchers.

It should also be noted that the bond mechanism for different types of GFRP bars embedded in concrete might significantly different because the manufacturing process of GFRP bars has not yet been unified. At present studies mainly focused on the degradation mechanism of GFRP bar reinforced concrete immersed in single aggressive environment (Robert et al. 2009; Yan and Lin 2017; Masmoudi et al. 2011; Zhou et al. 2011; Dong et al. 2016). However, the harsh environment in the actual field conditions is diverse. Some scholars (Masmoudi et al. 2011; Wang et al. 2018) chose exposure period or temperature as a parameter variable while failed to couple with other environmental factors. Besides, researchers from different countries chose parameter variables of specimen setup according to different standards (Hassan et al. 2016; Yan et al. 2017; Bazli et al. 2017), and consequently obtained various experimental results and conclusions. Moreover, it is worth mentioning that, so far, there is still no specific environmental condition involved in present corresponding design codes. In summary, it can be noted that the impacts of diverse aggressive environments on the bond performance have not been evaluated comprehensively and comparatively.

Utilizing 60 pullout specimens with the uniform size and setup condition, this paper conducted experimental investigations aimed at assessing the durability of bonding properties between 2 kinds of GFRP bars and concrete under different harsh solution environments with different exposure periods (150, 210 and 270 days). Further, the experimental methodologies in the current study possibly approach the site situations. Pullout specimens were designed to analyze the following issues: (1) the effect of different environmental conditions, namely tap water, saline solution and alkaline solution, on the bond performance between GFRP bar and concrete was studied; (2) the influence from resin type and immersion period on the bond strength was explored. All findings of this study try to contribute to a better understanding on long-term bonding performance of GFRP bar reinforced concrete subjected to diverse aggressive conditions.

\section{Experimental work}

\subsection{Materials}

\subsubsection{GFRP bars}

Two types of GFRP bars, namely glass-vinylester (GV) bar and glass-epoxy (GE) bar were adopted in the current study, as shown in Fig. 1(a). The GV bar in the color of brownish black was combined of continuous long glass fibers ( $65 \%$ by volume) and a vinylester resin $(35 \%$ by volume) using a pultrusion process, while the GE bar in a cream color was composed of $65 \%$ glass fibers and $35 \%$ epoxy resin using the same pultrusion process. The surfaces for two kinds of GFRP bars were all grooved in order to improve their bond performance in concrete. As shown in Fig. 1(b), the GV bar was grooved with the gap of $2.5 \mathrm{~mm}$, depth of $1 \mathrm{~mm}$ and spacing of $7 \mathrm{~mm}$, while the GE bar was fabricated with groove gap of $3 \mathrm{~mm}$, groove depth of $1 \mathrm{~mm}$, and groove spacing of $6 \mathrm{~mm}$. The inner and outer diameters of both GFRP bars were 10 $\mathrm{mm}$ and $12 \mathrm{~mm}$ [see Fig. 1(c)], respectively. Using the immersion test according to ISO 10406-1 (ISO 2015), the cross-sectional areas of two kinds of GFRP bars were measured and the nominal diameters were obtained with the approximately same value as $11.2 \mathrm{~mm}$, which was applied to the subsequent processing of experimental results. The tensile strengths for two kinds of GFRP bars were measured based on the Chinese Construction Industry Standard JG/T406-2013 “Glass Fibre Reinforced Plastics for Civil Engineering” (China JG/T 2013). The detailed physical and mechanical properties of applied GFRP bars are presented in Table 1.

\subsubsection{Concrete}

The mix proportion of the concrete used in pullout specimens is presented in Table 2. The 42.5 grade ordinary Portland cement was adopted herein. The continuous grade of coarse aggregate prepared with crushed stones was 5 to $20 \mathrm{~mm}$. The fine aggregate was made up of natural river sand with $2.53 \%$ water content, 2.71 fineness modulus and $1535 \mathrm{~g} / \mathrm{cm}^{3}$ bulk density. The strength grade of concrete was $\mathrm{C} 40$, which was designed based on the corresponding Chinese code for design of mix proportion. The $150 \mathrm{~mm}$-cubic concrete samples were prepared during the pouring of the specimens. After the standard curing in 28 days, the measured cubic compression strengths averaged 41.25 MPa. 
Table 1 Physical and mechanical properties of GFRP bars tested in current study.

\begin{tabular}{cccccccccc}
\hline Bar type & $\begin{array}{c}\text { Nominal diameter } \\
(\mathrm{mm})\end{array}$ & $\begin{array}{c}\text { Nominal } \\
\text { cross-sectional } \\
\text { area }\left(\mathrm{mm}^{2}\right)\end{array}$ & Fiber & Resin & $\begin{array}{c}\text { Surface } \\
\text { type }\end{array}$ & & \multicolumn{2}{c}{ Tensile strength, $f_{\mathrm{u}}$} & \multicolumn{2}{c}{ Elastic modulus, $E_{\mathrm{g}}$} \\
\cline { 6 - 11 } & & 98.1 & Glass & Vinylester & Grooved & 971.8 & $\begin{array}{c}\text { COV } \\
(\%)\end{array}$ & $\begin{array}{c}\text { Mean } \\
(\mathrm{GPa})\end{array}$ & $\begin{array}{c}\text { COV } \\
(\%)\end{array}$ \\
\hline GFRP(GV) & 11.2 & 98.7 & Glass & Epoxy & Grooved & 868.2 & 2.1 & 40.2 & 2.5 \\
GFRP(GE) & 11.2 & 98.1 &
\end{tabular}

Note: For each type of GFRP bar, 3 tensile specimens were tested and the nominal cross-sectional areas were used to calculate the tensile strength and elastic modulus.

Table 2 Composition and strength of concrete.

\begin{tabular}{cccccc}
\hline W/C ratio & $\begin{array}{c}\text { Water } \\
\left(\mathrm{kg} / \mathrm{m}^{3}\right)\end{array}$ & $\begin{array}{c}\text { Cement } \\
\left(\mathrm{kg} / \mathrm{m}^{3}\right)\end{array}$ & $\begin{array}{c}\text { Coarse aggregate } \\
\left(\mathrm{kg} / \mathrm{m}^{3}\right)\end{array}$ & $\begin{array}{c}\text { Fine aggregate } \\
\left(\mathrm{kg} / \mathrm{m}^{3}\right)\end{array}$ & 28-day cubic compressive strength (MPa) \\
\hline 0.40 & 175 & 438 & 1243 & 438 & 41.25 \\
\hline
\end{tabular}

\subsection{Design and preparation of pullout speci- mens}

A total of 60 pullout specimens ( $30 \mathrm{GV}$ bar-concrete and 30 GE bar-concrete pullout specimens, respectively) were prepared according to the Chinese Standard JG/T406-2013 (China JG/T 2013). The dimensions of the pullout specimen were $150 \mathrm{~mm} \times 150 \mathrm{~mm} \times 150 \mathrm{~mm}$. As shown in Fig. 2(a), the GFRP bar was embedded in the center of the cubic concrete, and the length of its bonded section was set as $60 \mathrm{~mm}$ according to the Chinese Standard, being a little more than 5 times of the nominal bar diameter. Based on former studies, the bond strength might be decreased along with the increasing of embedment length (Saleh et al. 2019; Achillides and Pilakoutas 2004). This is possibly owing to the influence from the non-uniformly distributed bonding stress along the embedment length, and the decreasing of bar dimension caused by the Poisson effect, which further reduce the mechanical bonding resistance (Huang et al. 2020). Besides, based on pull-out tests of GFRP reinforced cubes with bar diameter as $13.5 \mathrm{~mm}$ and different embedment length, bonding strength was confirmed to be decreased by around $30 \%$ together with increasing of embedment length from 2.0 to 10.0 times of bar diameter (Achillides and Pilakoutas 2004). While recognizing the effect of the embedment length on bonding strength, a fixed embedment length of around 5 times the bar diameter, was adopted herein, to primarily discuss the influence from various aggressive environments on bond behaviors.

Besides, in order to pour the concrete for specimens, a new type of formwork was created. There are 9 modules in total, including modules with chutes for assembly, and modules with opening holes in the center to pass through the GFRP bars and the PVC tube shown in Fig. 2. Through the use of bolt connections at key parts, the stability of the formwork during the vibrating process is strongly guaranteed. In addition, a related patent based on the above-mentioned invention has been applied (Ni et al. 2020), and relevant details can be found therein.

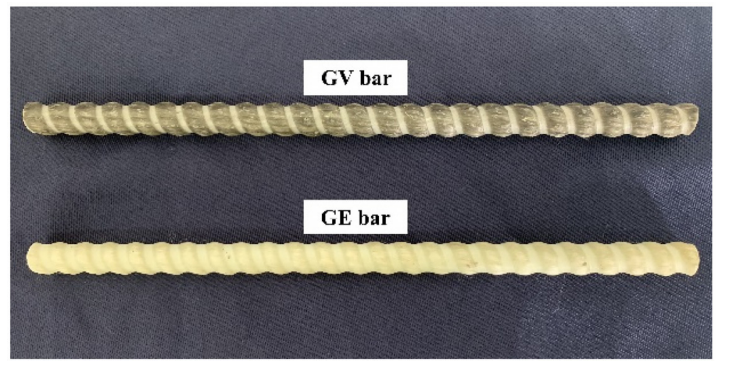

(a)

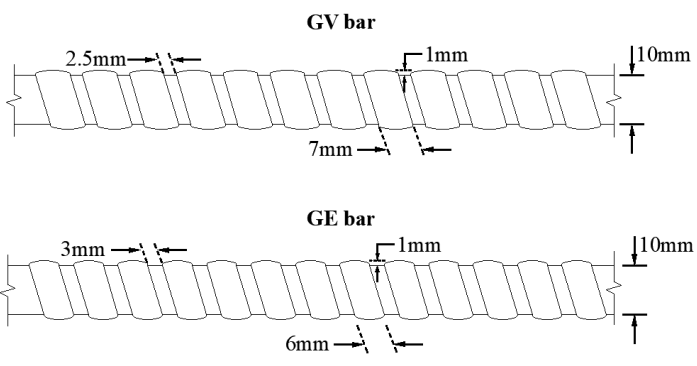

(b)

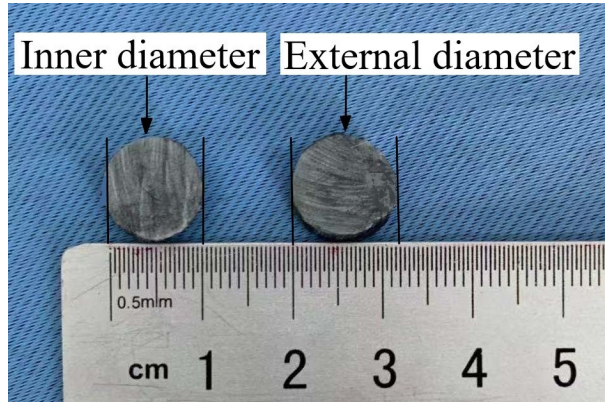

(c)

Fig. 1 GFRP bars used in this study: (a) Two types of GFRP bars; (b) Geometry of GFRP bars; (c) Close up of bar's cross-section. 
Table 3 Groups of pullout specimens.

\begin{tabular}{ccc}
\hline Bar type & Category of aggressive solution & Exposure period (days) \\
\hline GFRP $(\mathrm{GV})$ & Unconditioned & 0 \\
or & Alkaline solution & $150 / 210 / 270$ \\
GFRP $(\mathrm{GE})$ & Saline solution & $150 / 210 / 270$ \\
& Tap water & $150 / 210 / 270$ \\
\hline
\end{tabular}

For each type of GFRP bar, except for 3 unconditioned specimens serving as controlling samples, the other 27 specimens equally divided into 3 groups were partially immersed in three aggressive solutions for 150, 210, and 270 days of exposure [see Fig. 2(b)]. It should be noticed that for reducing the risk of failure in the pullout test and minimize the experimental error, all 3 specimens in each subdivided group were tested after the certain exposure period. Table 3 summarizes the arrangement of aggressive solutions, exposure periods and the number of tested specimens in this study.

\subsection{Environmental conditions}

As presented in Fig. 3, three kinds of aggressive solution environments, namely alkaline solution environment, saline solution environment and tap water environment, were prepared for specimens in pullout test. The design for the three aggressive solutions was as follows:

a) Alkaline solution environment: based on ACI 440.3R-04 (ACI 2004), the alkaline solution was prepared by adding $\mathrm{Ca}(\mathrm{OH})_{2}, \mathrm{KOH}$ and $\mathrm{NaOH}$ separately with the amount as $118.5 \mathrm{~g}, 4.2 \mathrm{~g}$ and $0.9 \mathrm{~g}$, into deionized water of $1 \mathrm{~L}$. The measured $\mathrm{pH}$ value was 12.9.

b) Saline solution environment: the saline solution was designed with the synthetic sea water, which mainly has the following compositions of $\mathrm{NaCl}$ for $24.54 \mathrm{~g} / \mathrm{L}$, $\mathrm{MgCl}_{2}$ for $5.2 \mathrm{~g} / \mathrm{L}, \mathrm{Na}_{2} \mathrm{SO}_{4}$ for $4.09 \mathrm{~g} / \mathrm{L}, \mathrm{CaCl}_{2}$ for $1.16 \mathrm{~g} / \mathrm{L}$ and $\mathrm{KCl}$ for $0.69 \mathrm{~g} / \mathrm{L}$ according to ASTM D665 standard (ASTM 2014). The measured $\mathrm{pH}$ value of the saline solution was 7.1.

c) Tap water environment: tap water in Zhenjiang (a city of Jiangsu Province, China) was used here.

\subsection{Test setup and procedures}

In order to prevent the GFRP bar from direct contacting the upper end clamp and slipping out of the fixture, the bar at the upper end was coated by using silica sands and thus mounted into a galvanized steel pipe with the length of $200 \mathrm{~mm}$ (see Fig. 4), followed by grouting epoxy resin before the test started. The pullout test was performed according to Chinese Standard JG/T406-2013 (China JG/T 2013). A UTM5000 electronic servo universal testing machine possessing the capacity of $200 \mathrm{kN}$ was applied to carry out the pullout test. As shown in Fig. 4, the test reaction frame is connected to the testing machine through a ball joint. The pressure plate of the reaction frame has a side length of $200 \mathrm{~mm}$ and a thickness of $25 \mathrm{~mm}$. As shown in Fig. 4(a), steel spacers were added between the upper end of the specimen and the pressure plate of the reaction frame to prevent stress concentration on the pressure plate and the possible deformation caused by it. Two electronic dial indicator with the maximum range as $30 \mathrm{~mm}$ and a displacement sensor with the measuring precision as $0.01 \mathrm{~mm}$ were utilized to measure the displacement in loaded end and free end of the GFRP bar, respectively.

For the unconditioned specimens, the pullout test was carried out after 28 days' standard curing. While for the conditioned specimens with a required exposure period, 3 samples were taken out from each aggressive solution tank and left in a dry environment with 24 hours. Before the start of the test, to avoid the inclination of the GFRP bar which may affect the result of bond strength, the load side with the galvanized steel pipe (Fig. 4) was put into the upper fixture and a tiny tension was applied to make the bar slightly stretched. Then the verticality of the bar

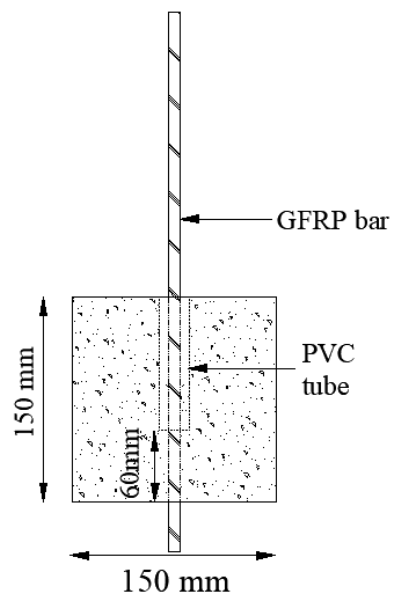

(a)

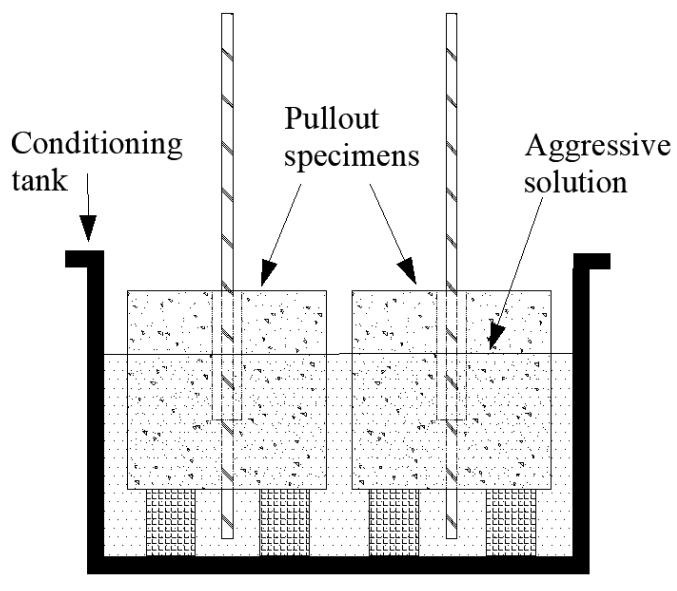

(b)

Fig. 2 Pullout specimens and their immersion in the aggressive solution: (a) Schematic diagram of pullout specimen; (b) Schematic for specimens placed in the conditioning tank. 
was tested by the bubble level and the position of the specimen was fine-tuned to ensure that the loading direction is consistent with the axial direction of the GFRP bar. Then the specimens received the effect of loading device for checking the bonding behavior. Further, only the effective test data were adopted for result analysis (specimens with pullout failure mode, being detailed later; after the test, the failure of the grouted resin between the GFRP bar and the galvanized steel pipe, the slippage of the bar at the resin interface as well as the slippage of the pipe to the loading fixture were observed in time, and any specimens with bar slippage in the loaded end have been excluded from the subsequent analysis of the results). The bond stress $\tau$ was calculated by assuming an even stress distribution in the bar's embedment section to evaluate the general bond performance, as shown in Eq. (1) (Bazli et al. 2017; Yan and Lin 2017).

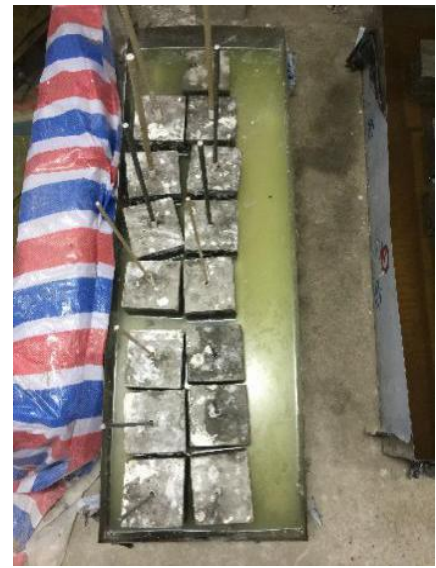

(a)

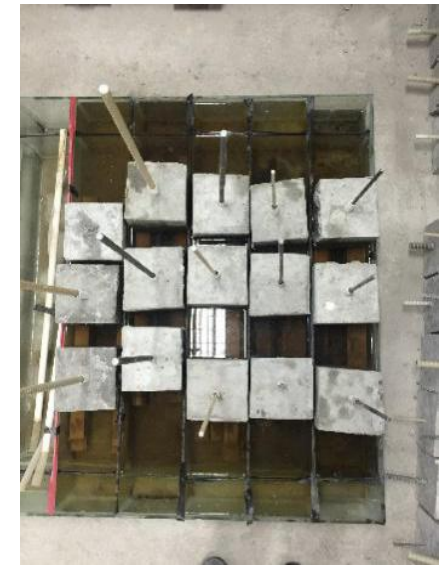

(b)

$$
\tau=\frac{F}{\pi d l_{e m b}}
$$

where $\tau$ is the bond stress (MPa); $F$ is the tensile load $(\mathrm{N})$; $d$ is bar's nominal diameter, which is $11.2 \mathrm{~mm}$ in this study; and $l_{\text {emb }}$ is the length of embedment, to be $60 \mathrm{~mm}$ herein. Further, $\tau$ corresponding to the ultimate load will be the bond strength named as $\tau_{\max }$.

Regarding the slip value of GFRP bar, a time lag with a smaller value in the same time point is confirmed for the measured displacement of the free end compared with that of the loaded end. This is considered to be caused by the non-uniform distribution of bonding stress along with the embedded section in practical situations. Thus, for evaluating the slip value distinctly, the measured displacement in the loaded end $\left(s_{m}\right)$ was treated as the basis. However, considering the elastic deformation $\left(\delta_{e}\right)$ existing in the unbonded section of GFRP bar, the actual slip value $(s)$ was defined as illustrated in Eqs. (2) and (3).

Fig. 3 Pullout specimens immersed in different solutions: (a) Alkaline environment; (b) Saline environment; (c) Tap water environment.

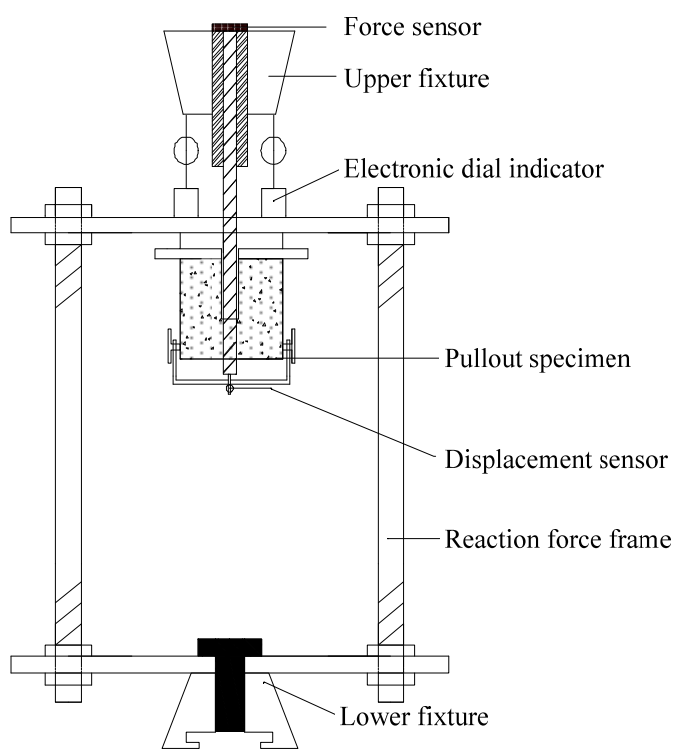

(a)

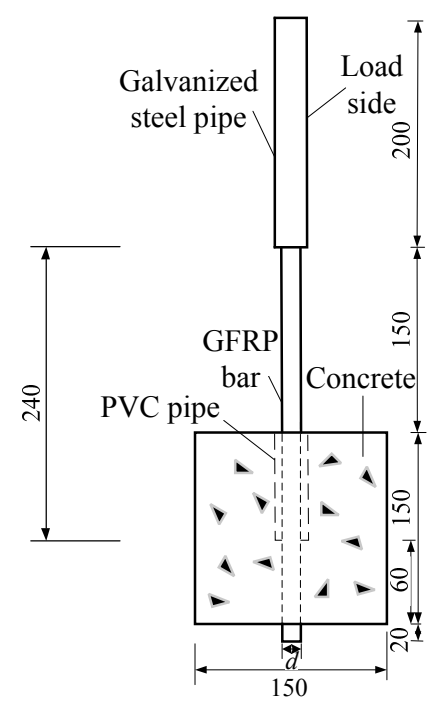

(b)

Fig. 4 Pullout test: (a) Schematic diagram of loading device; (b) Specimen setup. 
Table 4 Summary of pullout test results.

\begin{tabular}{|c|c|c|c|c|c|c|c|c|}
\hline \multirow{2}{*}{ Specimen ID } & \multicolumn{4}{|c|}{ Maximum bond strength $\tau_{\max }(\mathrm{MPa})$} & \multirow{2}{*}{$\begin{array}{l}\text { Standard } \\
\text { deviation }\end{array}$} & \multirow{2}{*}{$\begin{array}{l}\mathrm{CV} \\
(\%)\end{array}$} & \multirow{2}{*}{$\begin{array}{c}\text { Bond strength retention } \\
(\%)\end{array}$} & \multirow{2}{*}{$\begin{array}{l}\text { Failure } \\
\text { mode }\end{array}$} \\
\hline & No. 1 & No. 2 & No. 3 & Average & & & & \\
\hline GV-control & 16.99 & 18.66 & 17.47 & 17.71 & 0.70 & 3.97 & 100 & PF-1,2,3 \\
\hline GV-T-150 & 15.27 & 14.67 & 15.42 & 15.12 & 0.32 & 2.14 & 85.36 & PF-1,2,3 \\
\hline GV-T-210 & 12.08 & 13.95 & NA & 13.02 & 0.93 & 7.16 & 73.51 & $\begin{array}{c}\text { PF-1,2; } \\
\text { AF-3 }\end{array}$ \\
\hline GV-T-270 & 12.92 & 12.44 & 13.40 & 12.92 & 0.39 & 3.05 & 72.96 & PF-1,2,3 \\
\hline GV-S-150 & 14.24 & 13.38 & 14.71 & 14.11 & 0.55 & 3.90 & 79.67 & PF-1,2,3 \\
\hline GV-S-210 & 11.45 & 11.98 & 10.83 & 11.42 & 0.47 & 4.10 & 64.49 & PF-1,2,3 \\
\hline GV-S-270 & 11.10 & 9.90 & 10.24 & 10.41 & 0.50 & 4.85 & 58.81 & PF-1,2,3 \\
\hline GV-A-150 & 16.68 & 14.80 & NA & 15.74 & 0.94 & 5.99 & 88.87 & $\begin{array}{l}\text { PF-1,2; } \\
\text { AF-3 }\end{array}$ \\
\hline GV-A-210 & 13.47 & 11.93 & 12.44 & 12.61 & 0.64 & 5.09 & 71.21 & PF-1,2,3 \\
\hline GV-A-270 & 10.05 & 10.91 & 11.93 & 10.96 & 0.77 & 6.99 & 61.89 & PF-1,2,3 \\
\hline GE-control & 18.88 & 18.05 & 19.16 & 18.70 & 0.47 & 2.51 & 100 & PF-1,2,3 \\
\hline GE-T-150 & 14.44 & 16.01 & NA & 15.22 & 0.78 & 5.14 & 81.38 & $\begin{array}{l}\text { PF-1,2; } \\
\text { AF-3 }\end{array}$ \\
\hline GE-T-210 & 12.51 & 13.77 & 13.70 & 13.33 & 0.58 & 4.32 & 71.29 & PF-1,2,3 \\
\hline GE-T-270 & 11.98 & 12.94 & 13.59 & 12.84 & 0.66 & 5.15 & 68.65 & PF-1,2,3 \\
\hline GE-S-150 & 13.67 & 12.08 & 13.66 & 13.13 & 0.75 & 5.71 & 69.71 & PF-1,2,3 \\
\hline GE-S-210 & 10.98 & 9.94 & 9.99 & 10.31 & 0.48 & 4.64 & 54.86 & PF-1,2,3 \\
\hline GE-S-270 & 6.94 & 6.16 & 8.14 & 7.08 & 0.81 & 11.51 & 37.71 & PF-1,2,3 \\
\hline GE-A-150 & 11.21 & 12.04 & 14.26 & 12.50 & 1.28 & 10.30 & 66.67 & PF-1,2,3 \\
\hline GE-A-210 & 11.40 & 12.56 & 9.63 & 11.20 & 1.20 & 10.74 & 59.77 & PF-1,2,3 \\
\hline GE-A-270 & 9.77 & 9.30 & 13.84 & 10.97 & 2.04 & 18.59 & 58.62 & PF-1,2,3 \\
\hline
\end{tabular}

Note: $\mathrm{T}=$ Tap water environment; $\mathrm{S}=$ Saline environment; $\mathrm{A}=$ Alkaline environment; $\mathrm{PF}=$ Pullout failure; $\mathrm{AF}=$ Anchorage failure. NA indicates data not adopted because of anchorage failure.

$$
\begin{aligned}
& S=S_{m}-\delta_{e} \\
& \delta_{e}=\frac{F}{E_{g} \cdot A_{g}} l
\end{aligned}
$$

where, $E_{g}$ is the elastic modulus referred to Table $1 ; A_{g}$ is cross-sectional area of bar; and $l$ is the length of the unbonded section as $240 \mathrm{~mm}$ [refer to Fig. 4(b)].

\section{Experimental results and discussion}

\subsection{Failure modes}

During the loading process for pullout specimens, total 57 out of 60 GFRP bar reinforced specimens subjected a

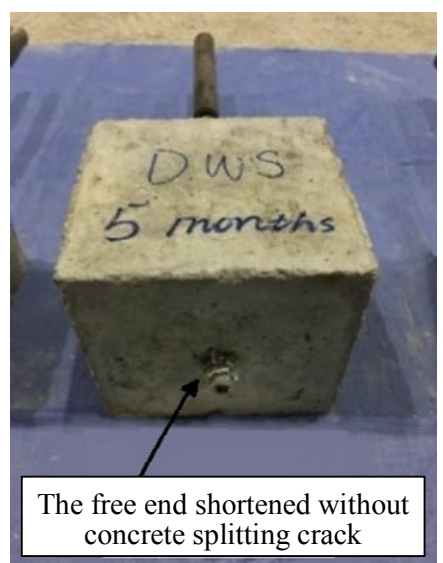

(a) typical failure mode as pullout failure $(\mathrm{PF})$, in which the bars were pulled out with no splitting crack occurred on the specimens [see Fig. 5(a)]. The remaining 3 specimens failed due to the slipping of the anchorage which was called anchorage failure (AF), as shown in Fig. 5(b). It should be pointed out that failure modes like concrete cracking and rebar rupture did not appear in this study. The failure modes of all specimens can refer to subsequent Table 4.

Similar to the bond behavior of steel bar reinforced concrete, the mechanism for bonding between FRP bar and concrete primarily relates to three components: adhesion, friction as well as mechanical bearing (Tighiouart et al. 1998). Owing to the difference in material performance and diversities of surface treatment for FRP

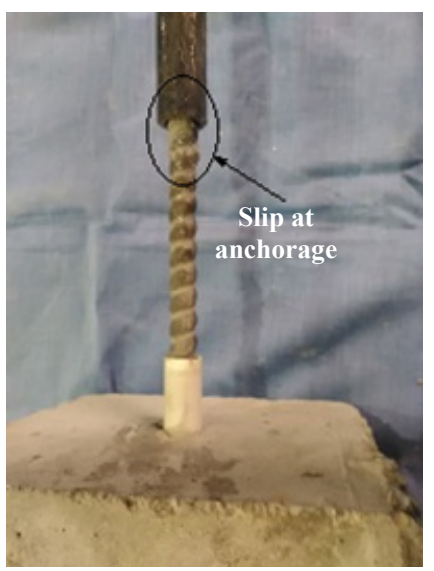

(b)

Fig. 5 Failure modes of the GFRP bar-concrete pullout specimens: (a) Pullout failure; (b) Anchorage failure. 
bars, Achillides and Pilakoutas (2004) believed that the bonding mechanism might be varied, while the transfer for the bond stress of ribbed bars mainly depended on the mechanical bearing, with the friction force and adhesion occupying a small part of the overall bonding strength. Compared with steel bar reinforced specimens, Gu et al. (2016) found that the GFRP bar-reinforced sample provided about $60 \%$ bond strength and had a longer slip length. In order to explore the bond and transfer mechanism of GFRP bar-concrete pullout specimens tested in the current study, the block concrete of pullout failure specimens was cut at the section near the bar-concrete interface, as shown in Fig. 6. It can be found that the typical pullout failure was achieved with undamaged rib and the sheared concrete remained in the gap of GFRP bar. Similar behaviors were observed for both conditioned and unconditioned tested pullout specimens. Based on above results, it is considered that the main bonding mechanism of grooved GFRP bar reinforced concrete should be mechanical bearing, which was also proved by Hassan et al. (2016).

\subsection{Bond stress vs. slip behavior}

Figures 7 to 9 display the representative correlations between bond stress and actual slip value obtained from Eqs. (1) to (3) for pullout specimens separately placed in

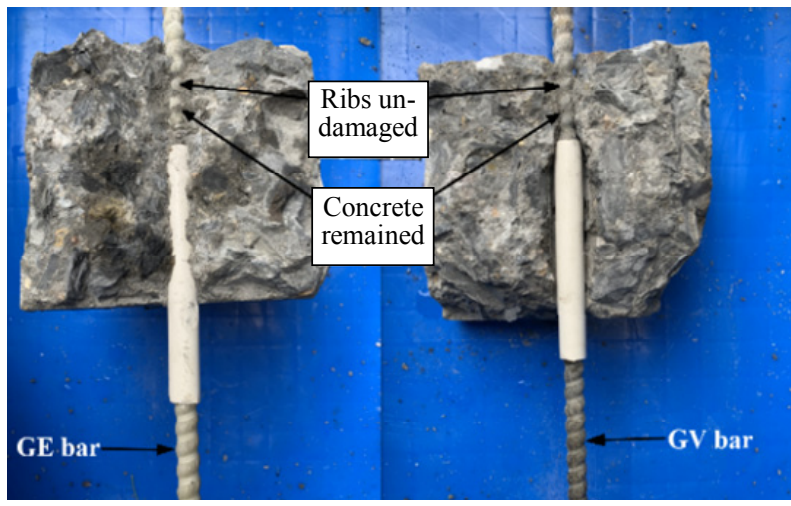

Fig. 6 Cross section cut around the GFRP bar-concrete interface.

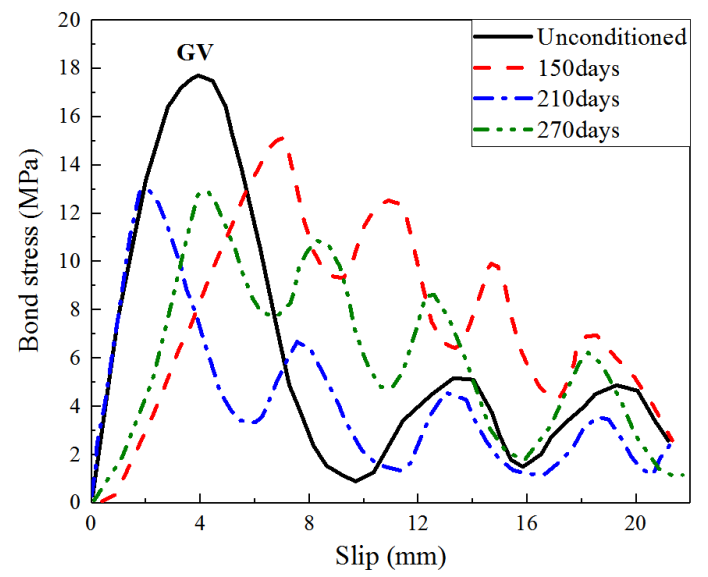

(a) tap water, saline solution as well as alkaline solution. According to Figs. 7 to 9, it is considered that for all the obtained bond stress vs. slip relationships, there is an initial rising stage before the maximum strength, and thus the bond stress decreases at a fluctuating but continual rate after reaching the maximum capacity. A similar degradation trend of bond stress-slip curves for FRP bars reinforced concrete was also confirmed by the experiments conducted by Wang et al. (2018) and Yang et al. (2018). Besides, Wang et al. (2018) suggested that these bond stress-slip curves generally consist of the following stages, namely micro-slip, slip, descending, and residual stage. From the curves plotted in Figs. 7 to 9 , it can be found that these four stages [for example, Fig. 7(b), OA: micro-slip stage, AB: slip stage, BC: descending stage, $\mathrm{CD}$ : residual stage] clearly occur in the GFRP bar-concrete pullout specimens tested in this study. In view of the fact that the adhesion between GFRP bar and concrete is small, the micro-slip stage in which the bond stress is mainly provided by adhesion is short for unconditioned GE bar samples, as shown in Figs. 7(b), 8(b) and 9(b). For unconditioned GV bar samples, this micro-slip stage is barely visible which means that the adhesion is negligible. Then in the next three stages, mechanical bearing force mainly provides the bond stress, which is examined in the above section. As a result, for unconditioned specimens, the peak bond stress of GE bar-concrete specimen is slightly higher than that of GV bar-concrete sample.

From Figs. 7 to 9, the following valuable observations can also be discovered: 1) the bond stress-slip curves of conditioned specimens emerge residual stage obviously compared with the unconditioned ones; 2) the peak bond stresses of the conditioned specimen determined after more than 150 days' immersion in aggressive solution are smaller than that of the unconditioned specimen; and 3 ) as the exposure period increases, the peak bond stress has the trend to decrease gently for almost all pullout specimens exposed to three types of environmental conditions.

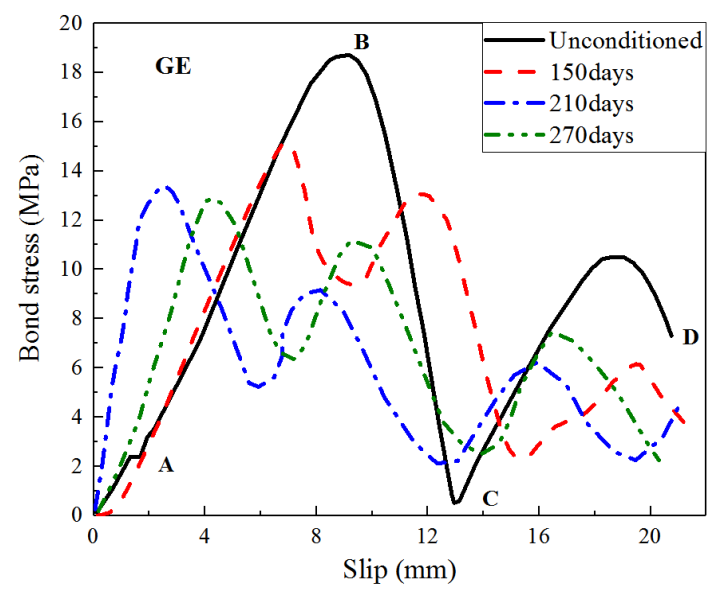

(b)

Fig. 7 Bond stress-slip curves of GFRP bar-concrete specimens immersed in tap water: (a) GV bar; (b) GE bar. 


\subsection{Bond strength}

According to Eq. (1), the bond strengths between GFRP bars and concrete in this experiment were calculated and the results were summarized in Table 4. As presented in Table 4, to distinguish the varieties of specimens, a specimen ID with three parts of annotations was adopted. For example, the notation of GE-T-150 indicates that the specimen composed of the GFRP bar with epoxy resin is exposed to tap water for 150 days.

As illustrated in Table 4, varying extents of reduction for the bonding strength of GFRP bar-concrete appeared after long immersion periods in tested environmental conditions. After 270 day's exposure, for instance, the average bond strength retention of GE bar-concrete specimens dropped to $37.71 \%, 58.62 \%$ and $68.65 \%$ in the saline, alkaline and tap water solutions, respectively. And for the GV bar-concrete specimens, the retention of average bond strength was reduced to be $58.81 \%$, $61.89 \%$ and $72.96 \%$ accordingly.

Regarding the degradation mechanism of GFRP bars in various solutions, water is considered to be able to invade the resin matrix of the bars, and free hydroxide ions cause the long intermolecular links of the matrix to break, which further induce local voids and micro-cracks
(Altalmas et al. 2015). Since the alkaline solution contains more hydroxide ions, this effect is considered more serious. In addition, between the resin matrix and the fiber, there is a thin layer of coupling agent, which is composed of salt-based materials that are impressionable to water and alkaline environments (Fergani et al. 2018). Therefore, water and alkaline solution can dissolve the coupling agent and cause local adhesion loss such as interface cracks and peeling. Furthermore, water can penetrate into the fiber position and cause its components to dissolve out. When the $\mathrm{pH}$ of the solution reaches a certain limit, it can destroy the silicon mesh in the fiber.

In addition to the above-mentioned effects of water, the saline solution can cause bubbles and solid substances on the surface of the bar, which promotes the deformation of the matrix and the dissolution of its components (Bazli et al. 2017). Therefore, based on the above-mentioned microscopic mechanism, various types of solutions can cause degradation of the mechanical properties of GFRP bar and its bonding with concrete to varying degrees, which can also be reflected by the test results obtained in this article. Besides, when for the same immersion solution and in the same exposure period, the bond strength of GE bar-concrete sample shows

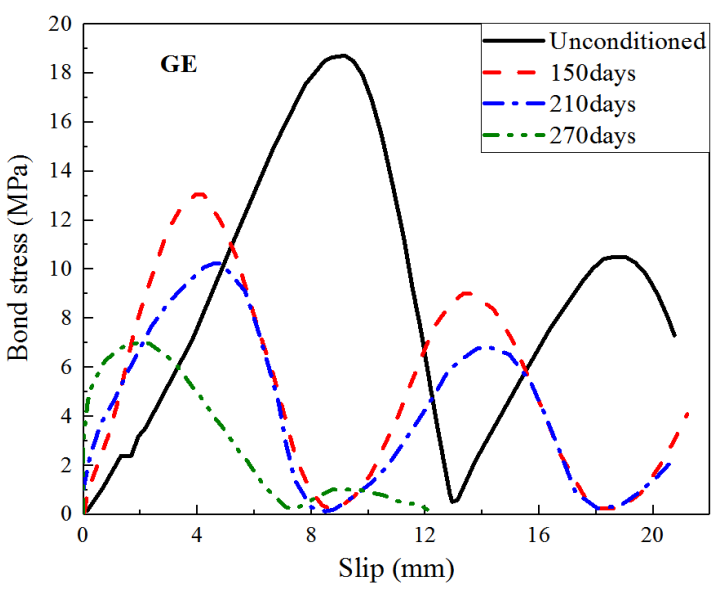

(b)

Fig. 8 Bond stress-slip curves of GFRP bar-concrete specimens immersed in saline solution: (a) GV bar; (b) GE bar.

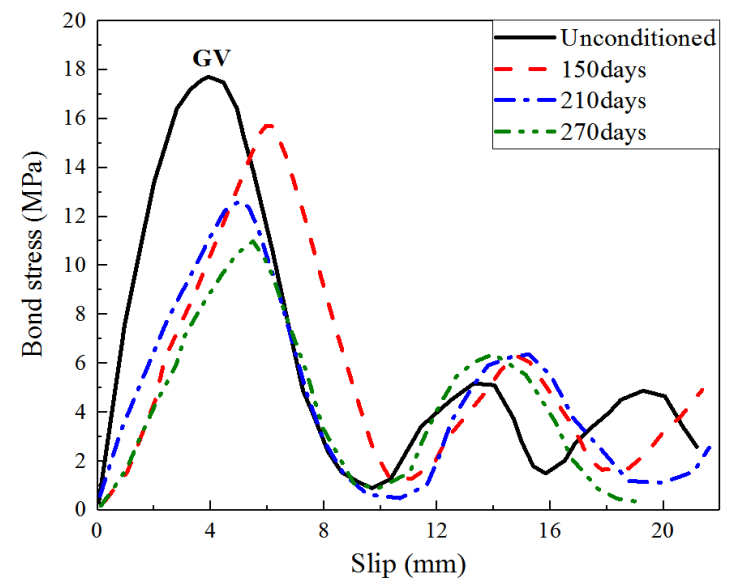

(a)

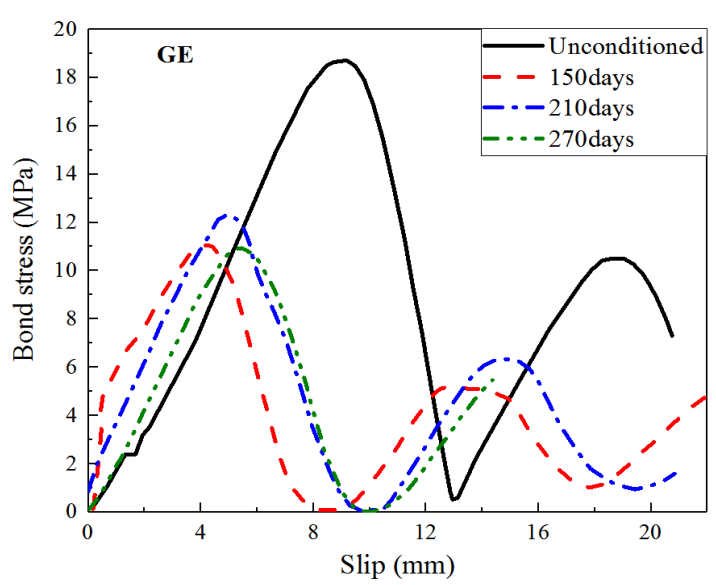

(b)

Fig. 9 Bond stress-slip curves of GFRP bar-concrete specimens immersed in alkaline solution: (a) GV bar; (b) GE bar. 
a more reduction compared with that of GV bar-concrete specimen, which will be further discussed later.

\subsection{Influence from resin type on bond strength}

The resin matrix is considered to have a great influence on the bonding strength and durability between GFRP bar and concrete elements. For the GFRP bars tested in the present study, two kinds of resin matrix, epoxy resin and vinylester resin, were used with the same resin volume fraction of $35 \%$. Based on the tested data given in Table 4, Fig. 10 shows all bond strengths for two kinds of GV and GE bar-concrete specimens immersed in tap water, saline and alkaline solutions after different periods of exposure. It can be seen from Fig. 10 that bonding strength has a remarkable degradation tendency for both GV and GE bar-concrete specimens with the increasing of exposure period. The gap in the boundary of GFRP bar and concrete induced by the aggressive solutions is considered to be responsible for this phenomenon. During the exposure in environmental solutions, some chemical irons will penetrate into concrete and fill these gaps, resulting in the constant deterioration of the GFRP bar's resin matrix, especially at the outer surface, which has a crucial effect on the degradation of bond strength (Hassan et al. 2016; Wang et al. 2018).

Regardless of the difference between the environmental conditions, the regressive analysis was attempted to demonstrate the degradation of bonding strength accompanied by the extension of exposure period with the fitting curves added in Fig. 10. Usually, the coefficient of determination $\mathrm{R}^{2}$ is desired to be close to 1.0 and recommended to reach an acceptable value with the minimum as 0.80 . For the GE bar-concrete specimens, however, the obtained value of $\mathrm{R}^{2}$ was 0.77 , which indicates that the test data of GE bar-concrete specimens are discrete and the GE bars have a more unstable property compared with the GV bars. Furthermore, it can be found from Fig. 10 that the slope of fitting line for GE

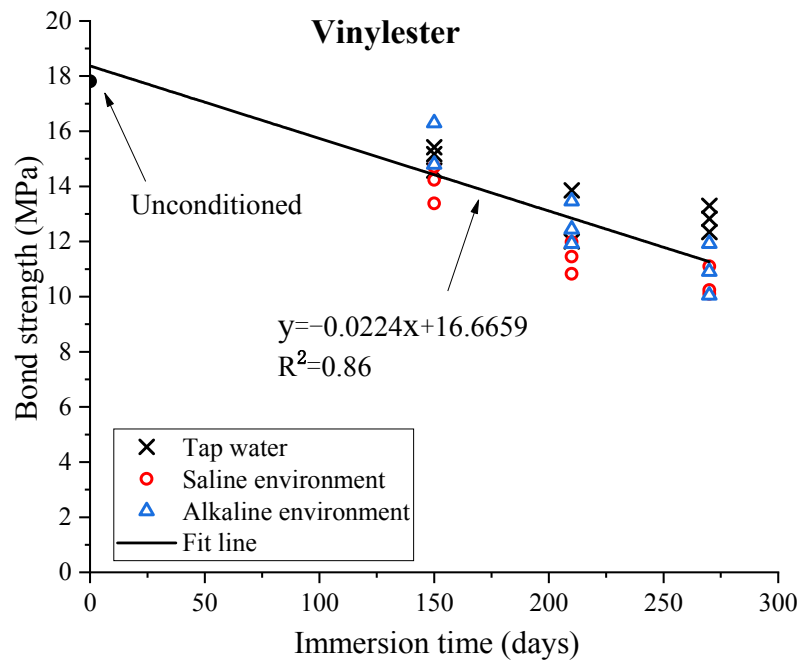

(a) bar-concrete specimens is a little greater than that for GV bar-concrete samples, and that the bonding strength values of GE bar-concrete specimens are in relatively smaller level compared with those of GV bar-concrete specimens in the same conditioned environment and exposure period. This outcome suggests that the vinylester resin has better long-term bond performance in these tested aggressive solutions than the epoxy resin. Dong et al. (2016) tested the bonding durability of BFRP bar-concrete with seawater environment for 30 and 60 days, and found that the average bond strengths of $\mathrm{BE}$ bar-concrete specimens were less than those of BV bar-concrete specimens. This finding reveals that the bond strength for BFRP bar with vinylester resin is better than with epoxy resin, which can approximately demonstrate the conclusion mentioned above.

\subsection{Influence from exposure period on bond strength}

Based on the obtained average values of bonding strength listed in Table 4, Figs. 11(a) and 12(a) depict the influence from exposure period on the bond strength between two kinds of GFRP bars and concrete exposed to tap water, saline and alkaline solutions. It is noticed that accompanied by the increment of exposure period, the bond strength generally presents a decline trend. The corresponding bond strength retentions for all specimens in three environmental conditions with various exposure periods are shown in Figs. 11(b) and 12(b).

In view of the degradation rate indicated in Figs. 11 and 12, it can be generally divided into 3 stages in the decline process of bonding strength herein, namely initial degradation stage (immersion time from 0 to 150 days), mid-degradation stage (immersion time from 150 to 210 days) and final degradation stage (immersion time from 210 to 270 days). Compared with the GV bar-concrete specimens (see Fig. 11), it is found from Fig. 12 that the bond strength of GE bar-concrete specimens basically

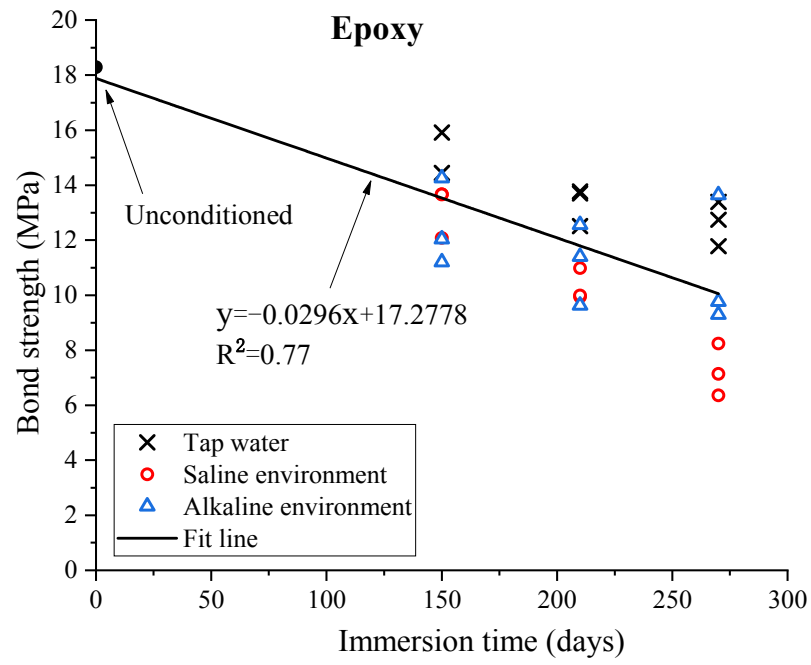

(b)

Fig. 10 All obtained data of bond strength after different periods of exposure: (a) GV bar-concrete specimens; (b) GE bar-concrete specimens. 
shows a faster descending trend in the initial degradation stage. It has been concluded above that the vinylester resin has a better durability in aggressive environments than that of epoxy resin, therefore the possible reason for this outcome is that the epoxy resin used in GE-bar concrete specimens has already deteriorated in the initial degradation stage (within exposure of 150 days). Besides, according to some experimental studies, the bonding strength of GFRP bar-concrete experienced a small increase (less than 10\%) after immersion in saline solution for 30 days (Wang et al. 2018) and 45 days (Dong et al. 2016). Therefore, it is speculated that during the beginning exposure period within around 45 days the bond strength of GFRP bar-concrete specimens might have slightly increased due to the swelling and strength enhancement of concrete (Dong et al. 2016). The possible developing trend of bond strength is considered as in- creasing firstly and then declining in the initial degradation stage from start to 150 days herein.

In the next two degradation stages (see Fig. 11), the bond strength of GV bar-concrete specimens tends to drop fast in the mid-degradation stage and shows a slow decline trend in the final degradation stage. For the GE bar-concrete specimens, the bond strength displays a gradual slowdown trend in the tap water and alkaline solutions while declines as fast as the initial stage in the saline solution, as shown in Fig. 12. By comparison, it can be concluded that for the GV bar-concrete specimens the vinylester resin matrix might be obviously damaged in the mid-degradation stage (from 150 to 210 days), resulting in a rapid decrease in bond strength (Hassan et al. 2016). After deterioration of resin matrix, the decline speed of bond strength in the final stage becomes slow for two kinds of GFRP bar-concrete specimens exposed

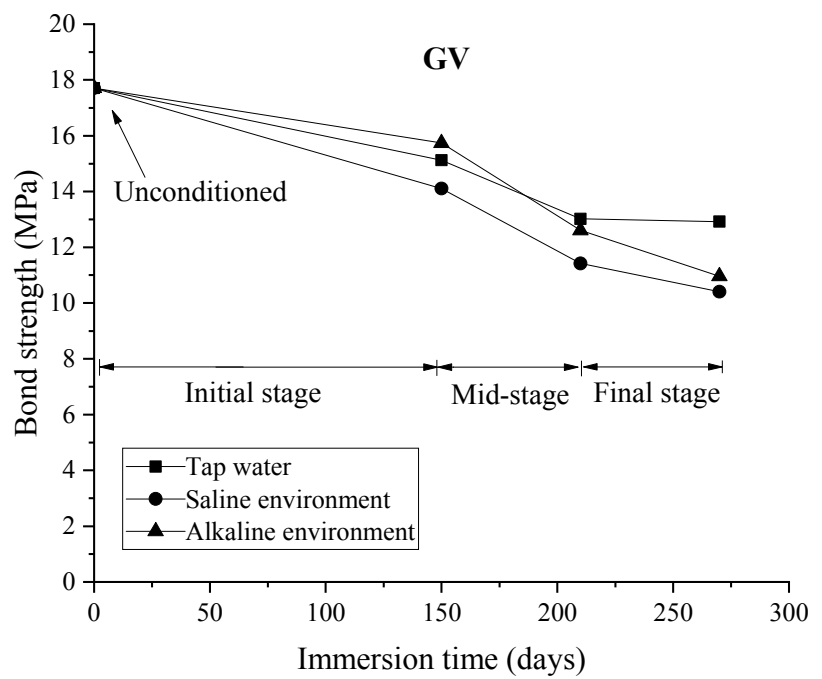

(a)

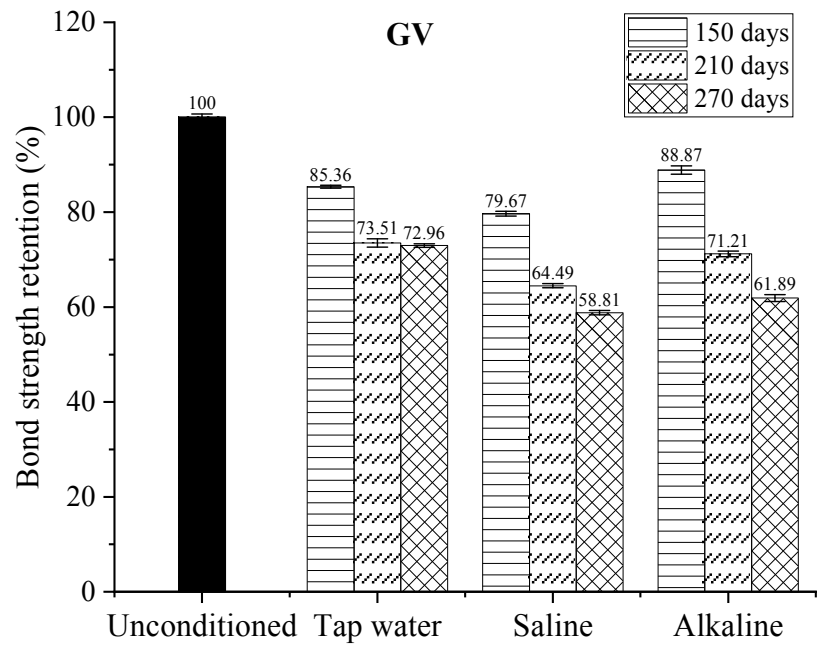

(b)

Fig. 11 Effect of immersion time on bond strength of GV bar-concrete specimens: (a) Average bond strength; (b) Bond strength retention.

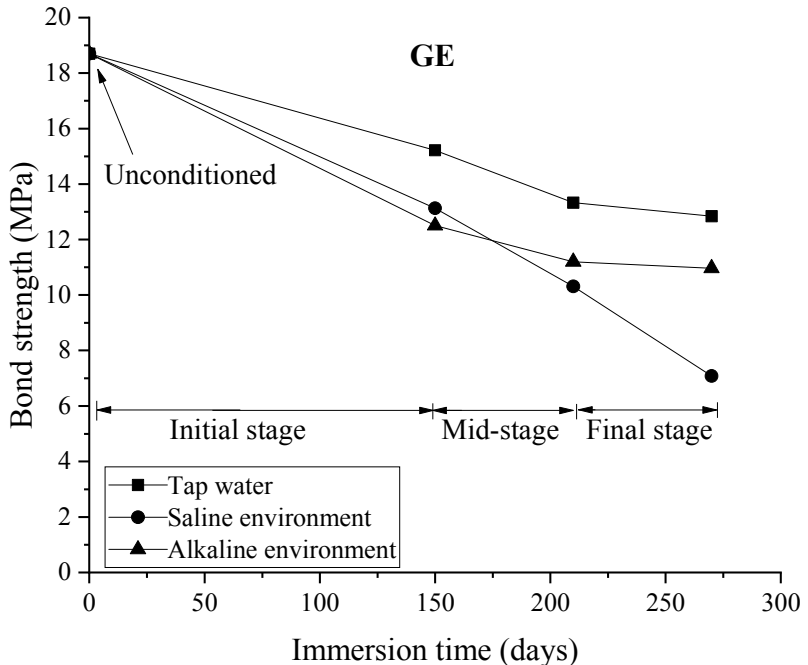

(a)

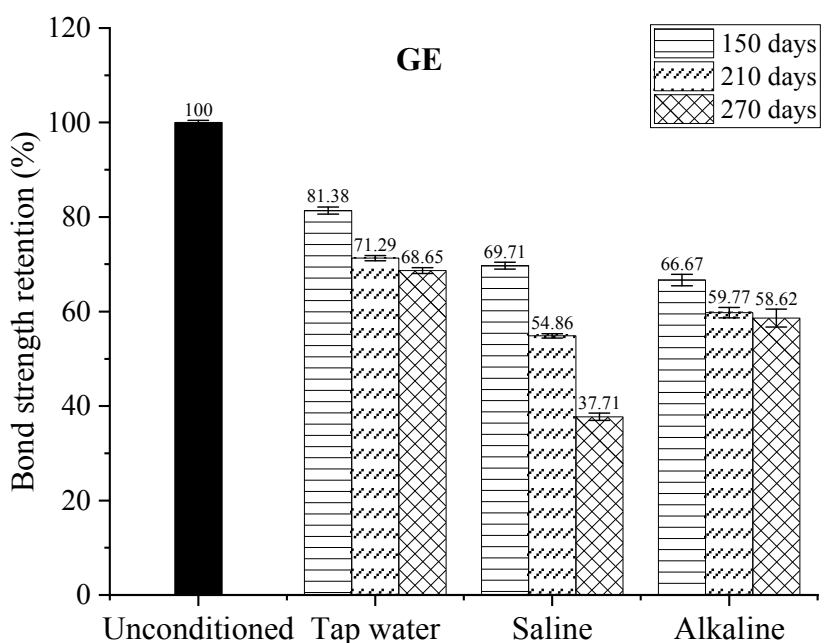

(b)

Fig. 12 Effect of immersion time on bond strength of GE bar-concrete specimens: (a) Average bond strength; (b) Bond strength retention. 
to tap water as well as alkaline solutions. The possible reason could be ascribed to the fact as the influence from the damaged resin matrix on bonding strength has tended to be stable and since then the degradation of bonding strength is supposed to be controlled by glass fibers.

\subsection{Comparison of the degradation of bond strength with existing results}

From Figs. 11 and 12, it is realized that the degradation for bonding strength of GFRP bar-concrete shows obvious differences in the three aggressive solutions used in this study. Besides, as described above, the degradation rate of bond strength also shows diversities with the increase of exposure period. Therefore, as shown in Fig. 13, taking the solution environment, exposure period and resin type into account, several existing results tested on GFRP bars with vinylester resin (Bazli et al. 2017; Wang et al. 2018) were selected to compare with our experimental data so as to accurately evaluate the degradation of the bonding performance. Besides, some experimental data obtained under elevated temperature of $60^{\circ} \mathrm{C}$ with shorter exposure period (Chen et al. 2007; Altalmas et al. 2015) were appended to Fig. 13. It is observed from Fig. 13 that as to the specimens immersed in the alkaline solution for 150 days, the rate of loss for bond strength obtained in the present test was roughly equal to the value obtained by Bazli et al. (2017) and in the range of two values got from the specimens with temperature as $60^{\circ} \mathrm{C}$ and exposure period as 60 days (Chen et al. 2007) and 90 days (Altalmas et al. 2015). While for the specimens exposed to the saline solution environment, the loss rate of bond strength tested after 150 days' immersion in this study is close to the results obtained after 120 days' immersion by Wang et al. (2018), and is higher than those given by Bazli et al. (2017) and Altalmas et al. (2015). It can be preliminarily concluded from above comparisons that regarding to the influence of aggressive solutions to bonding degradation of GFRP bars in con-

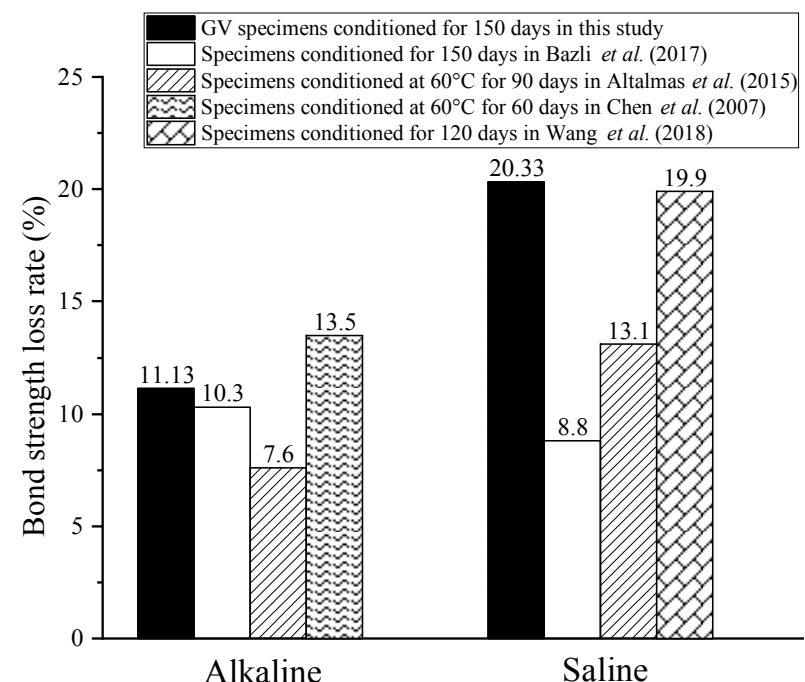

Fig. 13 Comparison of bond strength loss in alkaline and saline solutions with existing results. crete, the divergence of test results obtained in saline solution is more obvious than that shown in alkaline solution.

The bonding performance between GFRP bars and concrete is considered to be affected by many factors, such as the composition of the GFRP bar, the strength of the concrete and the composition of the aggressive solution, etc. Therefore, due to the use of various test and specimen conditions, the research results of different scholars in Fig. 13 are somewhat different. For example, with regard to alkaline solutions, the results of Chen et al. (2007) from immersion for 60 days at an elevated temperature of $60^{\circ} \mathrm{C}$ even exceed the results of the present test for 150 days and the results of Altalmas et al. (2015) at the same elevated temperature for 90 days. First of all, the increase in temperature may accelerate the degree of deterioration, which was also verified by Chen et al. (2007) and Wang et al. (2018). In addition, this difference may be also caused by the different compressive strength of concrete $\left[20 \mathrm{~N} / \mathrm{mm}^{2}\right.$ used by Chen et al. (2007), compared to about $41 \mathrm{~N} / \mathrm{mm}^{2}$ used in this test and $60 \mathrm{~N} / \mathrm{mm}^{2}$ or higher strength used by Altalmas et al. (2015)]. Lower strength may cause the concrete to be less dense or have more voids, which makes it easier for aggressive solutions to penetrate into the concrete and cause greater degradation of the bond strength.

As another example, for the saline solution in Fig. 13, the result of Bazli et al. (2017) for 150 days' immersion is less than the result of this test, which is similar to the result of Wang et al. (2018) for 120 days. This is most likely due to the different compositions of aggressive saline solutions since Bazli et al. (2017) used specific seawater obtained from the Persian Gulf, whereas this experiment and Wang et al. (2018) applied artificial seawater formulated according to specifications. Further, the result of 120 days from Wang et al. (2018) was similar to the results of 150 days from this test. The main reason is considered to be that the former used lower concrete compressive strength (maximum about 24 $\mathrm{N} / \mathrm{mm}^{2}$ ), as mentioned above, which may promote the deterioration degree. Currently, the influence from high alkalinity to the degradation of GFRP bars embedded in concrete is still controversial. Some previous studies (Won and Park 2006; Chen et al. 2007) believed that the high alkalinity in fresh concrete with $\mathrm{pH}$ value in the range of 12.5 to 13.5 will cause the deterioration of resin matrix and may aggravate the degradation of glass fiber in GFRP bars. By observing light microscopy, however, the surface of GFRP bar did not undergo significant degradation due to concrete's alkalinity in a long period, discovered by Mufti et al. (2005). From the experimental results in the current study shown in Fig. 11 as well as the comparative study given in Fig. 13, it seems that GFRP bars with vinylester resin possess the higher corrosion resistance to alkali comparing with salt, and they are compatible well with concrete. This conclusion coincides with the aforementioned analytical results. 


\section{Conclusions}

This paper explores the long-term bonding performance of GFRP bar reinforced concrete immersed in tap water, saline and alkaline solutions. According to the experimental results obtained in the current study, the following contents can be concluded:

(1) For total 60 GFRP bar-concrete pullout specimens tested in this study, most of them subjected the pullout failure mode, in which the bars were pulled out with no splitting crack appearing on the specimens, except for 3 specimens failed due to slip at the anchorage. The mode of pullout failure can be characterized by undamaged GFRP bar together with sheared concrete remained in gap of the bar.

(2) A similar varying tendency of bonding stress vs. slip curve was noticed in all untreated and treated specimens, which shows the initial rising trend until the peak stress value, and thus the decreasing process with a fluctuating but continual rate. However, the bonding stress vs. slip curves for treated test pieces emerge residual stage more obviously compared with the untreated ones. Accompanied by the increment of exposure period, the bonding strength decreases gradually for almost all treated specimens.

(3) After 270 days' exposure, the average bond strength retentions of $\mathrm{GV}$ bar-concrete specimens were $58.81 \%, 61.89 \%$ and $72.96 \%$ in saline, alkaline and tap water solutions, respectively. While the corresponding average retentions were $37.71 \%, 58.62 \%$ and $68.65 \%$ for GE bar-concrete specimens. It can be generally concluded that GFRP bars with vinylester resin has a better durability in tested aggressive environments than epoxy resin.

(4) Accompanied by the increment of exposure duration, there are generally 3 phases in the decline process of bonding strength in the GFRP bar-concrete specimens, namely initial degradation, mid-degradation and final degradation stage. The decline rate of bond strength is different during the 3 stages. For GV bar-concrete specimens, the downward of bond strength generally exhibits a slow trend in initial degradation stage, a faster trend in mid-degradation stage, and a slower trend in final degradation stage. For GE bar-concrete specimens, however, the slope of bond strength loss gradually decreases in tap water and alkaline solutions, while the downward trend depicts a linearly rapider decline in saline solution.

\section{Acknowledgements}

The authors gratefully acknowledge the financial support from the National Natural Science Foundation of China (Nos. 51878319 and 51578267) and the Jiangsu Planned Projects for Postdoctoral Research Funds (No. 2020Z350)

\section{References}

Achillides, Z. and Pilakoutas, K., (2004). "Bond behavior of fiber reinforced polymer bars under direct pullout conditions." Journal of Composites for Construction, 8(2), 173-181.

ACI, (2004). "ACI 440.3R-04: Guide test methods for fiber reinforced polymers (FRPs) for reinforcing or strengthening concrete structures." Farmington Hills, Michigan, USA: American Concrete Institute.

Altalmas, A., Refai, A. and Abed, F., (2015). "Bond degradation of basalt fiber-reinforced polymer (BFRP) bars exposed to accelerated aging conditions." Construction and Building Materials, 81, 162-171.

ASTM, (2014). "ASTM D665-14e1: Standard test method for rust-preventing characteristics of inhibited mineral oil in the presence of water." West Conshohocken, Pennsylvania, USA: American Society for Testing and Materials.

Baena, M., Torres, L., Turon, A. and Barris, C., (2009). "Experimental study of bond behaviour between concrete and FRP bars using a pull-out test." Composites Part B: Engineering, 40, 784-797.

Bazli, M., Ashrafi, H. and Oskouei, A. V., (2017). "Experimental and probabilistic models of bond strength between GFRP bar and different types of concrete under aggressive environments." Construction and Building Materials, 148, 429-443.

Borosnyoi, A., (2015). "Influence of service temperature and strain rate on the bond performance of CFRP reinforcement in concrete." Composite Structures, 127, $18-27$.

Bui, L. V. H., Stitmannaithumand, B. and Ueda, T., (2018). "Ductility of concrete beams reinforced with both fiber-reinforced polymer and steel tension bars." Journal of Advanced Concrete Technology, 16(11), 531-548.

Chen, Y., Davalos, J. F., Ray, I. and Kim, H. Y., (2007). "Accelerated aging tests for evaluations of durability performance of FRP reinforcing bars for concrete structures." Composite Structures, 78, 101-111.

China JG/T, (2013). "Construction Industry Standard JG/T 406-2013 of the People's Republic of China: Glass fibre reinforced plastics for civil engineering." Beijing: China Architecture and Building Press.

Dong. Z., Wu, G., Xu, B., Wang, X. and Taerwe, L., (2016). "Bond durability of BFRP bars embedded in concrete under seawater conditions and the long-term bond strength prediction." Materials \& Design, 92, 552-562.

Elgabbas, F., Vincent, P., Ahmed, E. A. and Benmokrane, B., (2016). "Experimental testing of basalt-fiber-reinforced polymer bars in concrete beams." Composites Part B: Engineering, 91, 205-218.

Fergani, H., Di Benedetti, M., Miàs Oller, C., Lynsdale, C. and Guadagnini, M., (2018). "Durability and degradation mechanisms of GFRP reinforcement subjected to severe environments and sustained stress." Construction and Building Materials, 170, 637-648.

Ge, W. J., Song W. R., Ashour, A. F., Lu, W. G. and Cao, D. F., (2020). "Flexural performance of FRP/steel 
hybrid reinforced engineered cementitious composite beams." Journal of Building Engineering, 31, Article ID 101329.

Gu, X. Y., Yu, B. and Wu, M., (2016). "Experimental study of bond performance and mechanical response of GFRP reinforced concrete." Construction and Building Materials, 114, 407-415.

Hassan, M., Benmokrane, B., Elsafty, A. and Fam, A., (2016). "Bond durability of basalt-fiber-reinforced-polymer (BFRP) bars embedded in concrete in aggressive environments." Composites Part B: Engineering, 106, 262-272.

Huang, H., Yuan, Y. J., Zhang, W., Hao, R. Q. and Zeng, J., (2020). "Bond properties between GFRP bars and hybrid fiber-reinforced concrete containing three types of artificial fibers." Construction and Building Materials, 250, Article ID 118857.

ISO, (2015). "ISO 10406-1: Fibre-reinforced polymer (FRP) reinforced of concrete - Test methods, Part 1: FRP bars and grids." Geneva, Switzerland: International Standards Association.

Koch, G. H., Brongers, M. P., Thompson, N. G., Virmani, Y. P. and Payer, J. H., (2002). "Corrosion cost and preventive strategies in the United States." Washington DC, USA: Federal Highway Administration, U.S. Department of Transportation.

Lu, C., Ni, Z., Chu, T. and He, L., (2020). "Comparative investigation on tensile performance of FRP bars after exposure to water, seawater, and alkaline solutions." Journal of Materials in Civil Engineering, 32(7), Article ID 04020170.

Ma, G. W., Huang, Y. M., Aslani, F. and Kim, T., (2019). "Tensile and bonding behaviours of hybridized BFRPsteel bars as concrete reinforcement." Construction and Building Materials, 201, 62-71.

Masmoudi, R., Masmoudi, A., Ouezdou, M. B. and Daoud, A., (2011). "Long-term bond performance of GFRP bars in concrete under temperature ranging from $20^{\circ} \mathrm{C}$ to $80^{\circ} \mathrm{C}$." Construction and Building Materials, 25, 486-493.

Micelli, F. and Nanni, A., (2004). "Durability of FRP rods for concrete structures." Construction and Building Materials, 18, 491-503.

Mufti, A., Onofrei, M., Benmokrane, B., Banthia, N., Boulfiza, M., Newhook, J., Bakht, B., Tadros, G. and Brett, P., (2005). "Durability of GFRP reinforced concrete in field structures." In: C. K. Shield, Ed. Proceedings of the 7th International Symposium on Fiber-reinforced Polymer Reinforcement for Reinforced Concrete Structures (FRPRCS-7), Kansas City, Missouri, USA 6-9 November 2005. Farmington Hills, Michigan, USA: American Concrete Institute.

Ni, M. Z., Lu, C. H., Xu, K., Xuan, G. Y. and Zhang, L. L., (2020). "A formwork for pull-out test of reinforcement embedded in concrete." Patent Application No. CN210525460U, China National Intellectual Property Administration, People's Republic of China. (in Chinese)
Robert, M., Cousin, P. and Benmokrane, B., (2009). "Durability of GFRP reinforcing bars embedded in moist concrete." Journal of Composites for Construction, 13(2), 66-73.

Ruan, X. J., Lu, C. H., Xu, K., Xuan, G. Y. and Ni, M. Z., (2020). "Flexural behavior and serviceability of concrete beams hybrid-reinforced with GFRP bars and steel bars." Composite Structures, 235, Article ID 111772.

Saleh, N., Ashour, A. and Sheehan, T., (2019). "Bond between glass fibre reinforced polymer bars and high-strength concrete." Structures, 22, 139-153.

Taha, A., Alnahhal, W. and Alnuaimi, N., (2020). "Bond durability of basalt FRP bars to fiber reinforced concrete in a saline environment." Composite Structures, 243, Article ID 112277.

Tighiouart, B., Benmokrane, B. and Gao, D., (1998). "Investigation of bond in concrete member with fibre reinforced polymer (FRP) bars." Construction and Building Materials, 12, 453-462.

Wang, L., Mao, Y., Lv, H., Chen, S. and Li, W., (2018). "Bond properties between FRP bars and coral concrete under seawater conditions at 30,60 , and $80^{\circ} \mathrm{C}^{\prime}$, Construction and Building Materials, 162, 442-449.

Won, J. P. and Park, C., (2006). "Effect of environmental exposure on the mechanical and bonding properties of hybrid FRP reinforcing bars for concrete structures." Journal of Composite Materials, 40, 1063-1076.

Yan, F. and Lin, Z., (2017). "Bond durability assessment and long-term degradation prediction for GFRP bars to fiber-reinforced concrete under saline solutions." Composite Structures, 161, 393-406.

Yan, F., Lin, Z. and Yang, M., (2016). "Bond mechanism and strength of GFRP bars to concrete: A review." Composites Part B: Engineering, 98, 56-69.

Yan, F., Lin, Z., Zhang, D., Gao, Z. and Li, M., (2017). "Experimental study on bond durability of glass fiber reinforced polymer bars in concrete exposed to harsh environmental agents: Freeze-thaw cycles and alkalinesaline solution." Composites Part B: Engineering, 116, 406-421.

Yang, S., Yang, C., Huang, M., Liu, Y., Jiang, J. and Fan, G., (2018). "Study on bond performance between FRP bars and seawater coral aggregate concrete." Construction and Building Materials, 173, 272-288.

Zhang, J., Jin, W. L., Mao, J. H., Long, J. X. and Zhong, X. P., (2020). "Deterioration of static mechanical properties of RC beams due to bond damage induced by electrochemical rehabilitation". Construction and Building Materials, 237, Article ID 117629.

Zhou, J., Chen, X. and Chen, S., (2011). "Durability and service life prediction of GFRP bars embedded in concrete under acid environment." Nuclear Engineering Design, 241, 4095-4102.

Zhou, J., Chen, X. and Chen, S., (2012). "Effect of different environments on bond strength of glass fiber-reinforced polymer and steel reinforcing bars." KSCE Journal of Civil Engineering, 16(6), 994-1002. 